Article

\title{
Design of U-Geometry Parameters Using Statistical Analysis Techniques in the U-Bending Process
}

\author{
Wiriyakorn Phanitwong *, Untika Boochakul and Sutasn Thipprakmas \\ Department of Tool and Materials Engineering, King Mongkut's University of Technology Thonburi, \\ Bangkok 10140, Thailand; Untika.bo@gmail.com (U.B.); sutasn.thi@kmutt.ac.th (S.T.) \\ * Correspondence: wiriyakorn.wp@gmail.com; Tel.: +66-2-470-9218
}

Received: 16 March 2017; Accepted: 10 June 2017; Published: 26 June 2017

\begin{abstract}
The various U-geometry parameters in the U-bending process result in processing difficulties in the control of the spring-back characteristic. In this study, the effects of U-geometry parameters, including channel width, bend angle, material thickness, tool radius, as well as workpiece length, and their design, were investigated using a combination of finite element method (FEM) simulation, and statistical analysis techniques. Based on stress distribution analyses, the FEM simulation results clearly identified the different bending mechanisms and effects of U-geometry parameters on the spring-back characteristic in the U-bending process, with and without pressure pads. The statistical analyses elucidated that the bend angle and channel width have a major influence in cases with and without pressure pads, respectively. The experiments were carried out to validate the FEM simulation results. Additionally, the FEM simulation results were in agreement with the experimental results, in terms of the bending forces and bending angles.
\end{abstract}

Keywords: U-bending; pad; finite element method; spring-back; analysis of variance (ANOVA)

\section{Introduction}

In recent years, with more severe requirements for industrial sheet-metal parts, complicated geometrical parts with high dimensional accuracy and difficult-to-form materials are increasingly needed. To fabricate these bent parts, owing to the merits of the die-bending process, which are that several kinds of shapes and sizes can be fabricated more quickly with low production-costs, the bending process is a common and widely-applied sheet-metal forming process. Spring-back is the the principal problem faced in formation and is the main barrier faced in product quality improvement in precision-bent parts. Various geometry and process parameters, including bend angle, material thickness, tool radius, and material properties, result in processing difficulties in the control of the spring-back feature. Therefore, the bending process has also been developed using different methods to achieve precision bent parts [1-7]. Zong et al. [1] studied spring-back evaluation in hot v-bending of Ti-6Al-4V alloy sheets. Their results showed the effects of punch radius and bending temperature on spring-back characteristics. By applying a smaller punch, a greater plastic deformation was generated. The results also illustrated that the shape of the bent parts more closely matched those of the required bent-shape parts when holding times were increased. Leu [2] investigated the effects of process parameters, including, lubrication, material properties, and process geometries, on the position deviation and spring-back of high-strength steel sheets, in order to develop process design guidelines for the asymmetric V-die-bending process. Kumar et al. [3] carried out experiments to determine the spring-back and thinning effects of aluminum sheet metal during L-bending operations. As clearance increased, the spring-back characteristics and fracture propagation increased. Lim [4] observed time-dependent spring-back in advanced high-strength steel (AHSS). The results showed that Young's moduli significantly affected both the initial spring-back and the 
time-dependent spring-back. Thipprakmas studied the punch height effect and coined-bend technique in the V-die-bending process [5,6], as well as proposing the side coined-bead technique to prevent the bead mark on the bend radius in the V-die-bending process [7].

As an industrial part, the U-shape of the channel, beam, and frame increasingly requires the aforementioned complicated geometry; high dimension precision is also needed. As the main problem in the bending process, spring-back is the key factor that affects the quality of complicated U-shaped parts. A great deal of research has been conducted on this in the past [8-18]. Jiang and Dai [8] proposed a novel model to predict U-bend spring-back and time-dependent spring-back for a high-strength low-alloy (HSLA) steel plate. Using this novel model, prediction was done at the stage of tool design and resulted in increased accuracy of the drawn part. Thipprakmas and Boochakul [9] investigated the effects of asymmetrical U-bent shapes, including bend angle and tool radius, on the spring-back characteristics and compared them with those in the case of a symmetrical U-bent shape. Phanitwong and Thipprakmas [10] proposed the centered coined-bead technique for precise fabrication of U-bent parts. Li et al. [11] investigated delamination using U-channel formation in the bending mode. Their results indicated that increases in the forming speed somewhat decreased the tendency towards delamination, and increases in the blank holding force significantly diminished the occurrence of delamination. The predictions of spring-back in cases of the $U$ stretch-bending process [12], and in the pre-strained U-draw/bending process [13], were investigated. Thipprakmas and Phanitwong [14] used the finite element method to analyze the bending mechanisms and spring-back/spring-go characteristics in various U-bending processes. Seong et al. [15] analyzed the core shear stress in welded deformable sandwich plates to prevent de-bonding failure during U-bending. To prevent failure during the bending phase of sandwich plates, it was recommended that the clearance be three times larger than the thickness of the sandwich plate. Marretta and Lorenzo [16] studied the influence of material property variability on spring-back and thinning in aluminum alloy sheet stamping of S-shaped U-channel processes. Tang et al. [17] proposed the mixed hardening rule, coupled with the Hill48' yielding function, to predict the spring-back of sheet U-bending. Zhang et al. [18] predicted spring-back and side wall curl after the U-bending process. The increases in the blank holding force and the friction between the sheet and die reduced the spring-back characteristics.

However, the geometry parameter design for controlling the spring-back characteristic has not yet been researched. In the present research, the effects of U-geometry parameters, including bend angle, tool radius, material thickness, channel width, and workpiece length were investigated, using finite element method (FEM) simulations. In addition, U-geometry parameter design was also examined using a combination of FEM simulations and statistical analysis techniques to determine the degree of importance of each U-geometry parameter. Experiments were carried out to validate the FEM simulation results. The FEM simulation results were in agreement with the experimental results, in terms of the bending forces and bending angles. Based on stress distribution analysis, the FEM simulation results clearly identified the different bending mechanisms and effects of the U-geometry parameters on the spring-back characteristic between U-bending U-geometry, with and without pressure pads. The statistical analysis of a central composite design (CCD) and analysis of variance (ANOVA) techniques were used out to examine the degree of importance of U-geometry parameters in relation to the spring-back feature. The statistical analysis results were able to specify the U-geometry parameters that markedly influence the spring-back characteristic, and yielded information about the degree of importance of each pro U-geometry parameter on the U-bending process. The results showed that the bend angle and channel width have a major influence on the spring-back feature, in cases with and without pressure pads, respectively.

\section{Finite Element Method (FEM) Simulations and Experimental Procedures}

\subsection{FEM Simulation Model}

The U-bending process is typically subdivided into two types of U-die-bending: with and without pressure pads [19]. Diagrams of the U-bending models investigated in the present study, with and 
without pressure pads, are shown in Figure 1. In the present research, to avoid the effects of pressure pads on the spring-back characteristics, a fixed pressure pad mode was set. Specifically, in the FEM simulations, a pressure pad was set by moving downward at the same velocity of the punch. This resulted in the workpiece being completely clamped by the punch and pressure pad during the bending phase. These U-bending models with three levels of channel width $(W)$, workpiece thickness $(t)$, bend angle $(\theta)$, punch radius $\left(R_{\mathrm{p}}\right)$, and workpiece length $\left(W P_{\mathrm{L}}\right)$, were examined. The details of the U-geometry parameter conditions investigated are listed in Table 1 . The two-dimensional, implicit quasi-static finite element method, as implemented in the commercial analytical code DEFORM-2D, was used for the FEM simulations. One half of the simulation model, with a two-dimensional plane strain simulation, was applied. The solution algorithm of the Newton-Raphson iteration was utilized in this FEM model. To prevent the divergence calculation due to excessive deformation of the elements, the adaptive remeshing technique was applied by setting every three steps. In accordance with past research $[9,10]$, the punch and die were set as rigid types, and the workpiece material was set as an elasto-plastic type. The workpiece was meshed and used approximately 4000 rectangular elements. An element size of approximately of $0.6 \mathrm{~mm}$ was generated overall for the workpiece, with the seven elements over the workpiece thickness. The fine element region was also generated on the bending allowance zone. In this zone, element sizes of approximately $0.2 \mathrm{~mm}$, and the 27 elements over the workpiece thickness, were generated. The workpiece material was A1100-O (Japanese Industrial Standards (JIS)) aluminum and the corresponding properties were obtained from tensile testing data. On the basis of the U-die-bending process, in the present research, the phenomenon of the cyclic loading of bending-unbending was not generated, and the Bauschinger effect could be neglected. The plastic properties of the workpiece were assumed to be isotropic and were described using the von Mises yield function. In the present research, based on the plane strain model of the U-die-bending process, which only focused on the longitudinal bend direction, the effects of material anisotropy were small and could be neglected. The elasto-plastic, power-exponent, isotropic hardening model was used, and the constitutive equation was determined from the stress-strain curve, as shown in Figure 2. The strength coefficient and the strain hardening exponent values were $153.5 \mathrm{MPa}$ and 0.2 , respectively. In addition, a plastic strain ratio in the rolling direction $\left(r_{0}\right)$ of 0.521 was observed. The other material properties are given in Table 1 , where $E, \sigma_{\mathfrak{u}}$ and $v$ denote, respectively, the Young modulus, ultimate tensile stress, and the Poisson's ratio. To define the accuracy of the friction coefficient, as per past research $[4,8,19]$, the contact surface model, defined by Coulomb friction law, was applied. By comparing the FEM simulation results obtained from each friction coefficient $(0.08,0.10$ and 0.12$)$ with the experimental results, the contact interfaces between the sheet and the tool, defined with a friction coefficient value of 0.10 , were in good agreement, which corresponded well with the literature $[10,13,14,16]$. The other process parameter conditions were designed as shown in Table 1.

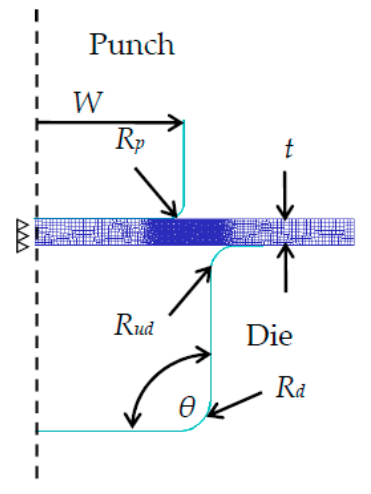

(a)

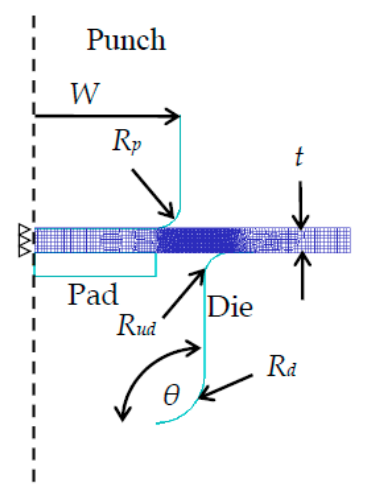

(b)

Figure 1. Finite element method (FEM) simulation model: (a) without pressure pad and (b) with pressure pad. 
Table 1. FEM simulation and experimental conditions.

\begin{tabular}{cc}
\hline Simulation Model & Plane Strain Model \\
\hline Object types & $\begin{array}{c}\text { Workpiece: Elasto-plastic } \\
\text { Punch/Die/Pad: Rigid }\end{array}$ \\
& A1100-O $(J I S)$ \\
Ultimate tensile stress $\left(\sigma_{\mathrm{u}}\right): 102.5 \mathrm{MPa}$ & Elongation $(\delta): 43.5 \%$ \\
Porkpiece material & Plastic anisotropy $\left(r_{0}\right): 0.521$ \\
& Young's modulus $(E): 69000 \mathrm{MPa}$ \\
Poisson's ratio $(v): 0.33$
\end{tabular}

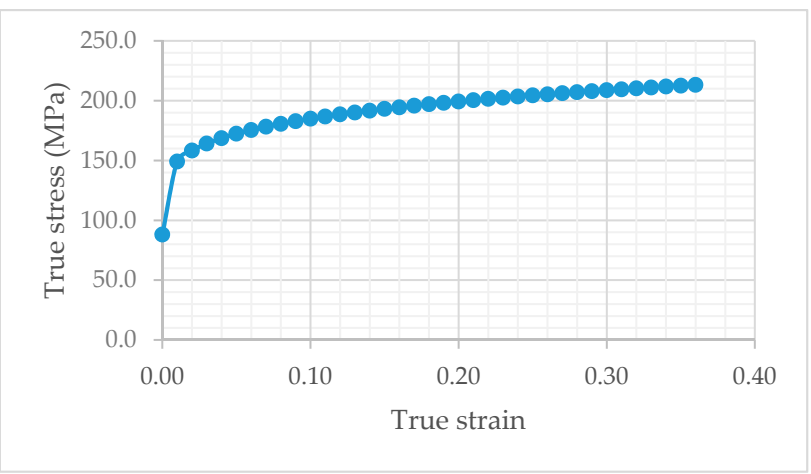

Figure 2. True stress-strain curve obtained from the tensile test.

\subsection{Experimental Procedures}

Validation of the FEM simulation results were done using laboratory U-bending experiments. As per the experiments in previous research [9,10], Figure 3 shows examples of the punch and die set for the U-bending experiments. A five-tonne universal tensile testing machine (Lloyd instruments Ltd., West Sussex, UK) was used as the press machine for the laboratory experiments. In the case with pressure pads, as shown in Figure 3a, the workpiece was clamped by the pad plate that was screwed on the punch. A geometrical comparison between the experimental geometry and the simulation-based geometry was performed, based on the obtained bend angles and workpiece thickness. Five samples from each bending condition were used to inspect the obtained bend angles and the workpiece thickness at the leg, bend radius, and bottom surface. The bend angle and workpiece thickness, after unloading, were measured using a profile projector (Model PJ-A3000, Mitutoyo, Kawasaki, Japan). The amount of spring-back and the workpiece thickness were calculated based on the obtained bend angles and the workpiece thickness. The average spring-back and workpiece thickness values, as well as the standard deviation (SD), were reported. The bending force was also recorded and compared with the bending force analyzed using FEM simulations. 


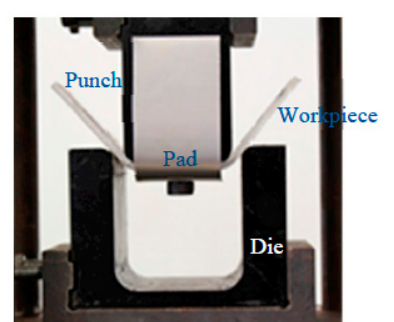

(a)

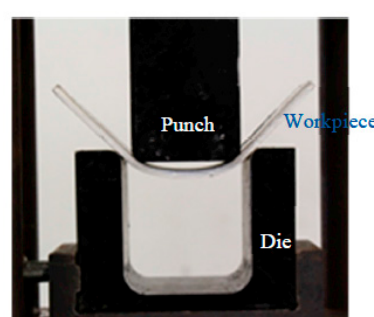

(b)

Figure 3. U-die sets for the experiments: (a) without pressure pad and (b) with pressure pad.

\subsection{Statistical Analysis Techniques}

To examine the degree of importance of the U-geometry parameters in relation to the spring-back characteristic, first, the central composite design technique was used to plan the experimental design for the FEM simulations. The three levels of the five parameters, channel width $(W)$, workpiece thickness $(t)$, bend angle $(\theta)$, punch radius $\left(R_{\mathrm{p}}\right)$, and workpiece length $\left(W P_{\mathrm{L}}\right)$, were applied, as shown in Table 2. The ANOVA technique was also applied to illustrate the degree of importance of each parameter that markedly influenced the spring-back characteristic, as depicted in the Equation (1):

$$
\% \text { Contributions } \text { treatment }=\left[S S_{\text {treatment }} / S S_{\text {total }}\right] \times 100
$$

where $S S_{\text {treatment }}$ and $S S_{\text {total }}$ represent the treatment sum of squares and the total sum of squares, respectively.

Table 2. U-geometry parameters and their levels.

\begin{tabular}{|c|c|c|c|c|c|}
\hline \multirow{2}{*}{\multicolumn{2}{|c|}{ Parameters }} & \multicolumn{3}{|c|}{ Parameter Levels } & \multirow{3}{*}{$\begin{array}{c}\text { Units } \\
\mathrm{mm}\end{array}$} \\
\hline & & \multirow{2}{*}{$\begin{array}{c}\text { Low } \\
30\end{array}$} & \multirow{2}{*}{$\begin{array}{c}\text { Medium } \\
45\end{array}$} & \multirow{2}{*}{$\begin{array}{c}\text { High } \\
60\end{array}$} & \\
\hline Channel width $(W)$ & $\begin{array}{l}\text { With pad } \\
\text { With no pad }\end{array}$ & & & & \\
\hline Bend angle $(\theta)$ & $\begin{array}{c}\text { With pad } \\
\text { With no pad }\end{array}$ & 90 & 105 & 120 & $\circ$ \\
\hline Workpiece length $\left(W P_{\mathrm{L}}\right)$ & $\begin{array}{l}\text { With pad } \\
\text { With no pad }\end{array}$ & 120 & 125 & 130 & $\mathrm{~mm}$ \\
\hline Tool radius $\left(R_{\mathrm{p}}\right)$ & $\begin{array}{c}\text { With pad } \\
\text { With no pad }\end{array}$ & $\begin{array}{l}5 \\
3\end{array}$ & $\begin{array}{l}6 \\
4\end{array}$ & $\begin{array}{l}7 \\
5\end{array}$ & $\mathrm{~mm}$ \\
\hline Workpiece thickness $(t)$ & $\begin{array}{c}\text { With pad } \\
\text { With no pad }\end{array}$ & $\begin{array}{l}3 \\
1\end{array}$ & $\begin{array}{l}4 \\
2\end{array}$ & $\begin{array}{l}5 \\
3\end{array}$ & $\mathrm{~mm}$ \\
\hline
\end{tabular}

\section{Results and Discussion}

\subsection{Effects of U-Geometry Parameters on the Spring-Back Characteristic}

\subsubsection{Channel Width}

Figure 4 shows a comparison of the stress distribution analyzed in the workpiece, before unloading, with respect to the various channel widths in the cases of a U-bending process with and without pressure pads. By using a pressure pad, a bending characteristic could not be formed across the punch radius during the bending phase. This resulted in bending stress being generated in the bending allowance zone (bend radius zone) and a low reversed bending stress being generated on the legs. Reversed bending stress is the stress generated by the bending phenomena, where the generated compressive and tensile stresses are formed on the opposite side of those formed in the bending allowance zone. These stress distribution analyses generally agree with those reported in the literature [14]. For the aforementioned stress characteristics, the same level of generated bending stress 
on the bending allowance zone and the reversed bending stress on legs could be obtained as the channel width increases; the measured length of the generated stresses are shown in Figure 4a. This manner of the stress distribution analysis corresponded well with bending theory and the literature; the changes in bending stress generated in the bending allowance zone did not depend on the channel width, but rather, depended on the bend radius and bend angle $[10,20]$. In contrast, in the case where no pressure pad was used, the bending characteristic was formed across the punch radius during bending phase, as reported in the literature $[9,10]$. Based on the bending moment theory, the more the channel width increased, the more the bending characteristics formed across the punch radius increased. This resulted in the bending stress characteristics being generated on the bottom surface, as well as the reversed bending stress characteristic generated on the legs, as shown in Figure $4 \mathrm{~b}$. Specifically, the generated reversed bending stress on the bottom increased, but the generated reversed bending stress on the legs decreased slightly as the channel width increased; the measured length of the generated stress is listed in Figure $4 \mathrm{~b}$. These stress distribution analyses corresponded well with bending theory and the literature $[9,10]$. After compensating these stress distribution analyses, as per previous research $[5,7,9,10]$, the amount of spring-back was predicted, and is depicted in Figure 5 . The results showed that, as the channel width increased, the amount of spring-back was reasonably consistent in the case of a pressure pad being used. The results of spring-back prediction agreed well with the aforementioned stress distribution analysis, and also corresponded well with bending theory and the literature [20]. Specifically, in the case where a pressure pad was used, the stress distributions were analyzed at the same level, with respect to channel widths, and resulted in the same level of predicted spring-back characteristics. On the other hand, with the aforementioned stress distribution analysis in the case of no pressure pad, the results showed that the spring-go characteristic increased as the channel width increased. This behavior also generally agrees with that which is reported in the literature [10].

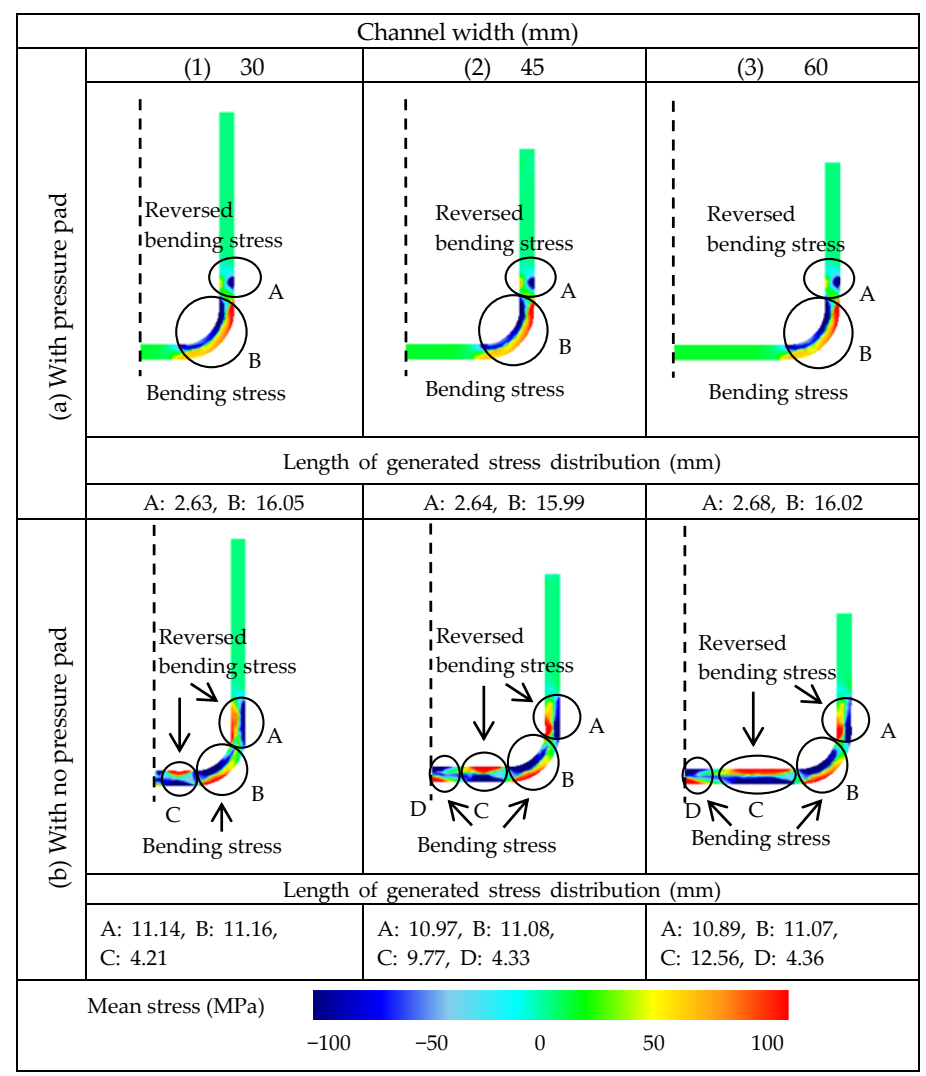

Figure 4. Comparison of the stress distribution analyzed in the workpiece, before unloading, with respect to various channel widths $\left(\theta: 90^{\circ}, R_{\mathrm{p}}: 7 \mathrm{~mm}, t: 3 \mathrm{~mm}, W P_{\mathrm{L}}: 120 \mathrm{~mm}, R_{\mathrm{ud}}: 5 \mathrm{~mm}\right)$. 


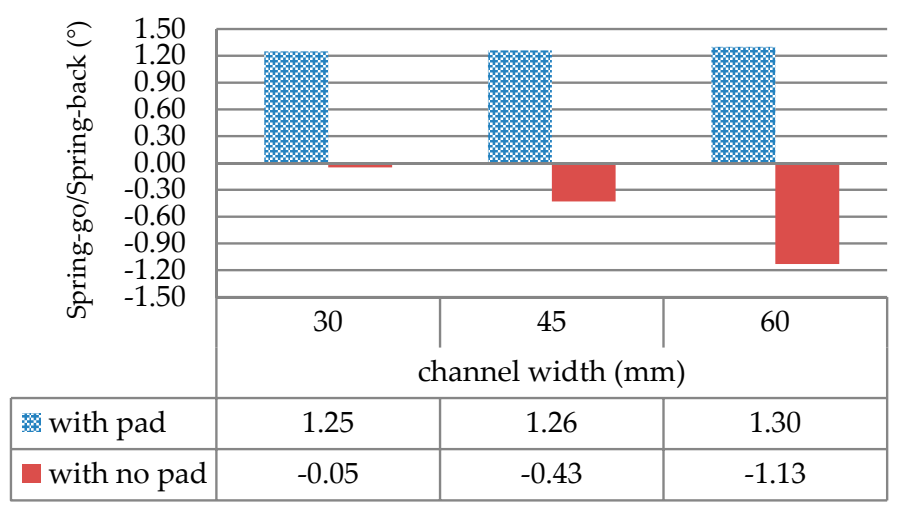

Figure 5. Comparison of the predicted spring-back/spring-go in cases of U-bending, with and without pressure pads, with respect to channel widths $\left(\theta: 90^{\circ}, R_{\mathrm{p}}: 7 \mathrm{~mm}, t: 3 \mathrm{~mm}, W P_{\mathrm{L}}: 120 \mathrm{~mm}, R_{\mathrm{ud}}: 5 \mathrm{~mm}\right)$.

\subsubsection{Workpiece Thickness}

A comparison of the stress distribution analyzed in the workpiece, before unloading, with respect to workpiece thicknesses in the cases of the U-bending process, with and without pressure pads, is shown in Figure 6. In the case where a pressure pad was used, the workpiece thickness affected the bending stress and reversed the bending stress characteristics in the bending allowance and the leg zones. This could be explained by the fact that changes in workpiece thickness resulted in increases in the outer bend radius, as well as in increases in the length of bending allowance zone over the bend radius. This manner of stress distribution analysis, again, corresponded well with bending theory and the literature, where changes in bending stress generated in the bending allowance zone depended on the bend radius $[10,20]$. Specifically, as the workpiece thickness increased, the bending stress characteristics in the bending allowance zone increased. In addition, the reversed bending stress characteristics on the legs increased as the workpiece thickness increased. However, with the measured length of the generated stress shown in Figure 6a, the increase in bending stress characteristic in the bending allowance zone was smaller than the increase in reversed bending characteristic on the legs. After compensating the stress distribution analyses, the amount of spring-back decreased as the workpiece thickness increased (depicted in Figure 7). This behavior generally agrees with that which is reported in the literature, that spring-back characteristics decreased as workpiece thickness increased [20]. On the other hand, in the case where no pressure pad was used, the results showed that there was a decrease in bending stress characteristics, on the bottom and in the bending allowance zone as the workpiece thickness increased. As per previous research $[9,10]$, the bending characteristic had difficulty forming across the punch radius during the bending phase as the workpiece thickness increased. This resulted in the bending stress characteristic not being formed, on the bottom surface, and the reversed bending characteristic was more easily formed on the legs in the case where a large workpiece thickness was applied. Therefore, the results showed an increase in the reversed bending stress characteristics on the legs, as measured by the length of the generated stress (Figure 6b). Again, after compensating these stress distribution analyses, the amount of spring-back decreased as the workpiece thickness increased, as shown in Figure 7. It was also observed, that the decrease in the spring-back characteristic in the case where no pressure pad was used, was larger than that in the case of a pressure pad being used. 


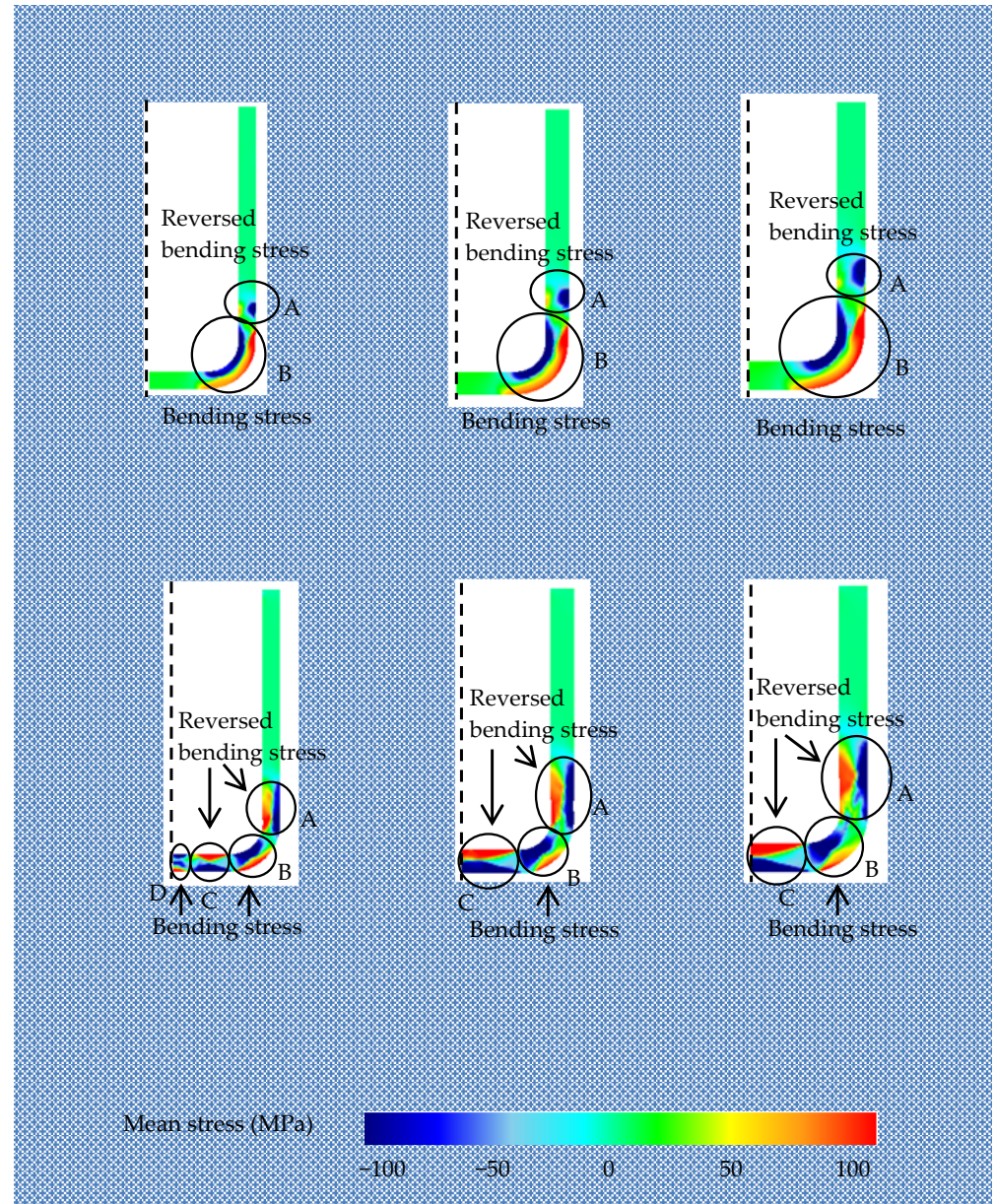

Figure 6. Comparison of the stress distribution analyzed in the workpiece, before unloading, with respect to various workpiece thicknesses $\left(\theta: 90^{\circ}, R_{\mathrm{p}}: 5 \mathrm{~mm}, W: 30 \mathrm{~mm}, W P_{\mathrm{L}}: 120 \mathrm{~mm}, R_{\mathrm{ud}}: 5 \mathrm{~mm}\right)$.

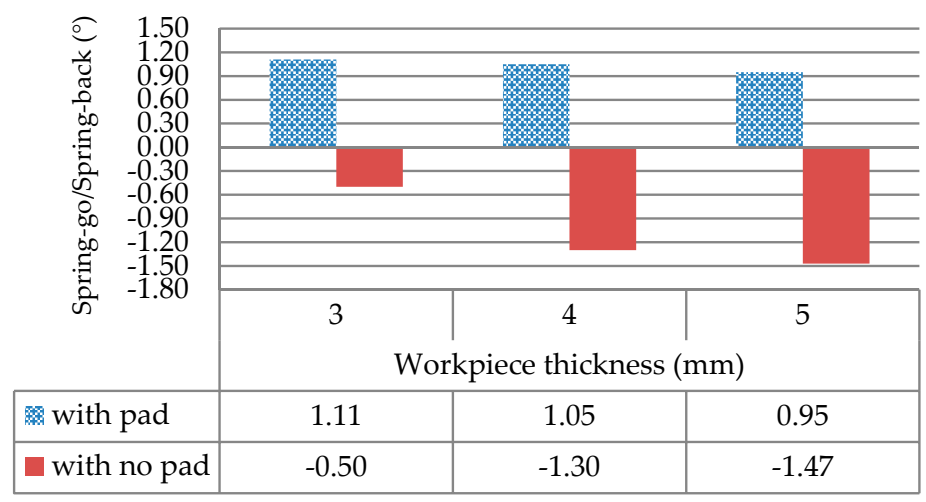

Figure 7. Comparison of the predicted spring-back/spring-go between the cases of U-bending with and without pressure pads, with respect to workpiece thicknesses $\left(\theta: 90^{\circ}, R_{\mathrm{p}}: 5 \mathrm{~mm}, W: 30 \mathrm{~mm}, W P_{\mathrm{L}}\right.$ : $\left.120 \mathrm{~mm}, R_{\mathrm{ud}}: 5 \mathrm{~mm}\right)$.

\subsubsection{Bend Angle}

Figure 8 shows a comparison of the stress distribution analyzed in the workpiece, before unloading, with respect to the various bend angles in the cases of the U-bending process, with and without pressure pads. With the use of pressure pads, according to past research [14], the bending and reversed bending stress characteristics were generated in the bending allowance and in the leg 
zones. It could be explained that the changes in bend angle directly resulted in changes in the bending allowance zone over the bend radius. Specifically, the larger the bend angle applied, the smaller the bending allowance zone obtained. This change resulted in the bending and reversed bending stress characteristics being decreased and increased as the bend angle increased, respectively, as measured by the length of generated stress (Figure 8a); these corresponded well with bending theory and the literature $[10,20]$. After compensating these stress distribution analyses, the amount of spring-back decreased as the bend angle increased, as depicted in Figure 9; these results corresponded well with bending theory and the literature [20]. In the case where no pressure pad was used, according to previous research $[9,10]$ and based on the bending moment theory, the bend angle affected the bending characteristic that formed across the punch radius during bending phase, and affected the bending stress and reversed bending stress characteristics in the bottom surface and leg zones. This resulted in reversed bending stress characteristics in the leg zone decreasing, and the bending stress characteristic on the bottom increasing, as shown in Figure 8b, which corresponded well with bending theory and the literature $[9,10,14]$. After compensating for these stress distribution analyses, the increase in the bending stress characteristics was larger than the increase in the reversed bending characteristics; the measured length of the generated stress is listed in Figure 8b. This resulted in the increase in the amount of spring-back as the bend angle increased, as shown in Figure 9. These amounts of spring-back, again, corresponded well with bending theory and the literature [9].

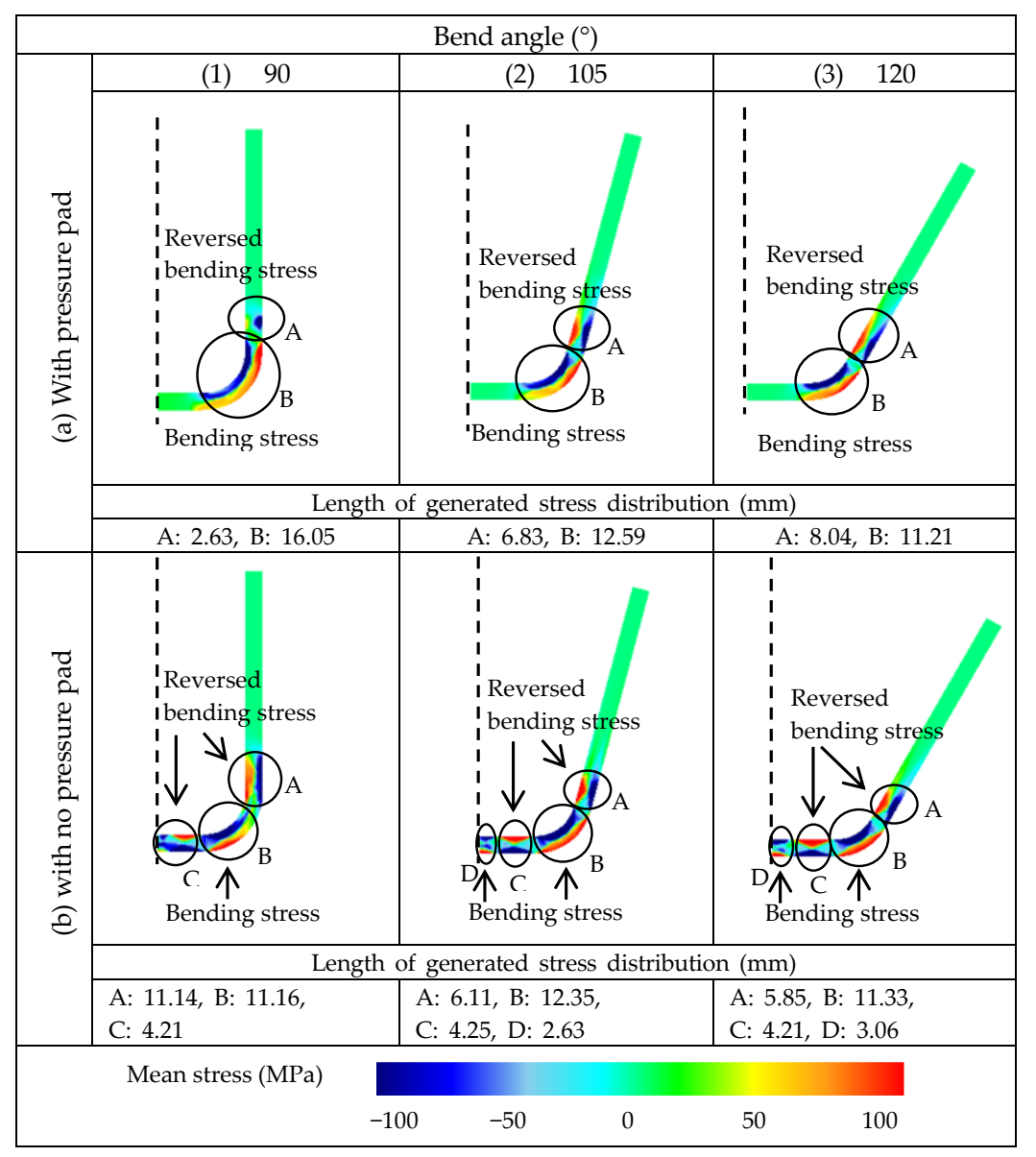

Figure 8. Comparison of the stress distribution analyzed in the workpiece, before unloading, with respect to various bend angles $\left(R_{\mathrm{p}}: 7 \mathrm{~mm}, W: 30 \mathrm{~mm}, t: 3 \mathrm{~mm}, W P_{\mathrm{L}}: 120 \mathrm{~mm}, R_{\mathrm{ud}}: 5 \mathrm{~mm}\right)$. 


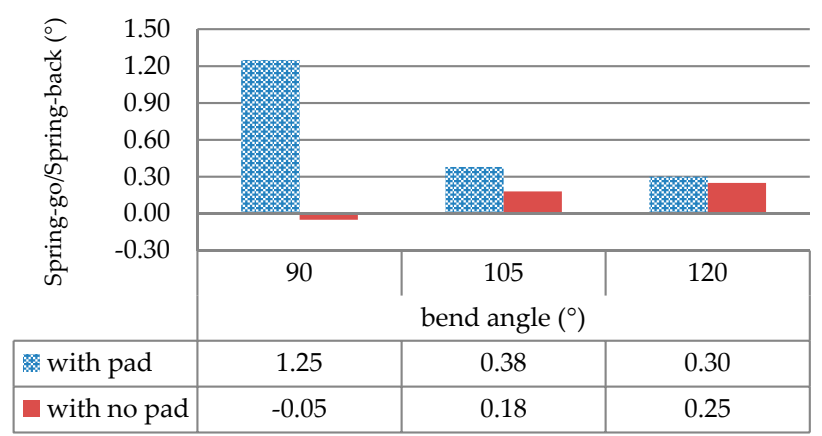

Figure 9. Comparison of the predicted spring-back/spring-go characteristics between the cases of U-bending, with and without pressure pads, with respect to bend angles $\left(R_{\mathrm{p}}: 7 \mathrm{~mm}, W: 30 \mathrm{~mm}, t: 3 \mathrm{~mm}\right.$, $\left.W P_{\mathrm{L}}: 120 \mathrm{~mm}, R_{\mathrm{ud}}: 5 \mathrm{~mm}\right)$.

\subsubsection{Tool Radius}

Figure 10 shows a comparison of the stress distribution analyzed in the workpiece, before unloading, with respect to various punch radii, in the cases of the U-bending process, with and without pressure pads. With the use of a pressure pad, as per past research [14,20], the bending stress characteristic was generated over the tool radius and a small reversed bending stress was generated on the legs, as shown in Figure 10a. The results showed that, as the punch radius increased, the bending stress characteristic increased; however, the reversed bending stress remained somewhat constant. These results corresponded well with bending theory and the literature, in that the tool radius directly affected the bending allowance zone and was increased as the tool radius increased [20]. After compensating these stress distribution analyses, the amount of spring-back increased as the tool radius increased, as shown in Figure 11. These results corresponded well with bending theory and the literature [20]. In the case where no pressure pad was used, the tool radius affected the bending stress and the reversed bending stress characteristics in the bottom surface and leg zones, which corresponded well with bending theory and the literature $[9,10,14]$. Specifically, the tool radius, not only affected the bending allowance zone, but it also affected the bending characteristics formed across the punch radius during the bending phase, and resulted in the change in bending stress and the reversed bending stress characteristics in the bottom surface and leg zones. It was observed that, as the tool radius increased, the increase in the bending stress characteristic was larger than the increase in the reversed bending characteristic; the measured length of the generated stress is listed in Figure 10b. This resulted in the increase in the amount of spring-back as the tool radius increased, as shown in Figure 11. These stress distribution analyses, and the amount of spring-back, corresponded well with bending theory and the literature $[9,10]$.

\begin{tabular}{|c|c|c|c|}
\hline \multicolumn{4}{|c|}{ Tool radius $(\mathrm{mm})$} \\
\hline \multirow{10}{*}{ 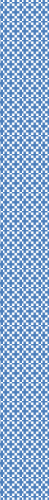 } & (1) & (2) 6 & (3) \\
\hline & & | & \\
\hline & i & & \\
\hline & & & \\
\hline & & & \\
\hline & Reversed & Reversed & $\begin{array}{l}\text { I Reversed } \\
\text { I bending stress }\end{array}$ \\
\hline & bending stress & & $\vartheta_{\mathrm{A}}$ \\
\hline & Bending stress & Bending stress & Bending stress \\
\hline & \multicolumn{3}{|c|}{ Length of generated stress distribution $(\mathrm{mm})$} \\
\hline & A: 2.70, B: 12.6 & A: $2.66, \mathrm{~B}: 15.4$ & A: 2.63, B: 16.05 \\
\hline
\end{tabular}

Figure 10. Cont. 


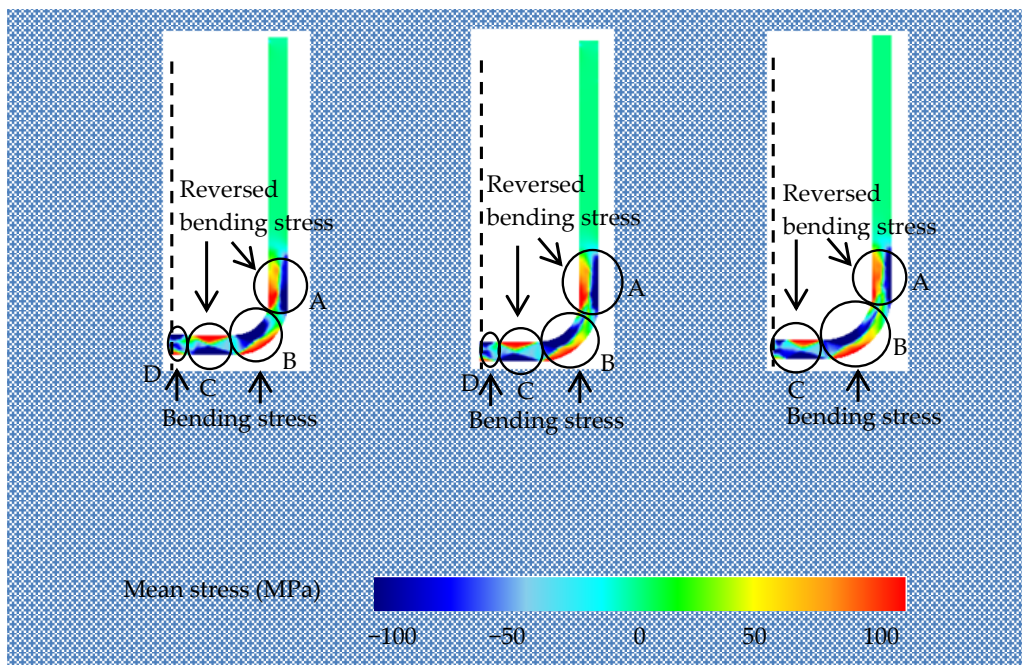

Figure 10. Comparison of the predicted spring-back/spring-go characteristics between the cases of U-bending, with and without pressure pads, with respect to tool radius $\left(\theta: 90^{\circ}, W: 30 \mathrm{~mm}, t: 3 \mathrm{~mm}\right.$, $\left.W P_{\mathrm{L}}: 120 \mathrm{~mm}, R_{\mathrm{ud}}: 5 \mathrm{~mm}\right)$.

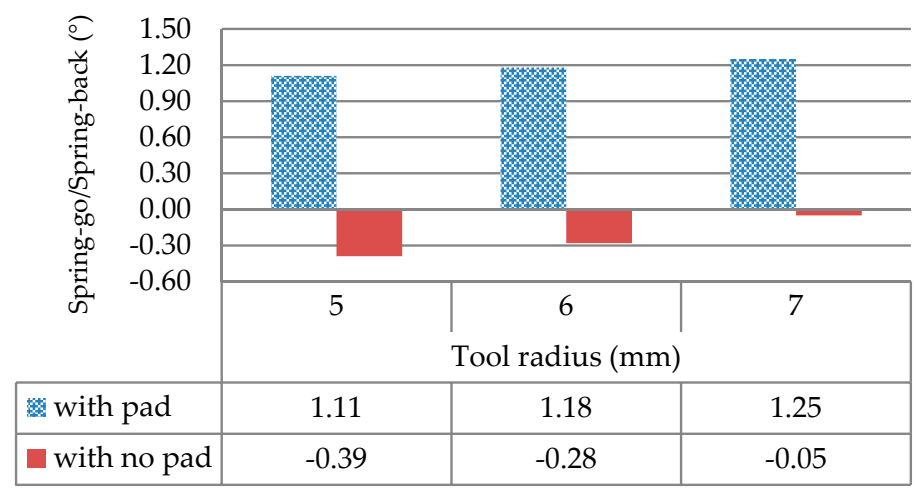

Figure 11. Comparison of the predicted spring-back/spring-go characteristics between the cases of U-bending, with and without pressure pads, with respect to tool radii $\left(\theta: 90^{\circ}, W: 30 \mathrm{~mm}, t: 3 \mathrm{~mm}\right.$, $W P_{\mathrm{L}}: 120 \mathrm{~mm}, R_{\mathrm{ud}}: 5 \mathrm{~mm}$ ).

\subsubsection{Workpiece Length}

Figure 12 shows a comparison of stress distribution, analyzed in the workpiece, before unloading, with respect to various workpiece lengths, in the cases of the U-bending process with and without pressure pads. As the workpiece length increased, the bending stress and reversed bending characteristics were somewhat constant in the case of pressure pads being used; additionally, the bending stress and reversed bending stress characteristics were somewhat constant in the case where no pressure pad was used. It could be explained that, based on the bending moment theory, the workpiece length rarely had any effect on the bending characteristics formed across the punch radius during the bending phase, and this resulted in the same level of bending and reversed bending stress characteristics being generated on the workpiece. In cases where pressure pads and no pressure pads were used, the amounts of spring-back and spring-go were also somewhat constant, respectively, as the workpiece length increased (Figure 13). The aforementioned effects of U-geometry parameters on spring-back/spring-go characteristics, including channel width, workpiece thickness, bend angle, tool radius, and workpiece length, were clearly identified; in the case of pressure pads being used, the channel width and workpiece length did not have any effect on the spring-back/spring-go characteristics, but only workpiece length did not have any effects on spring-back characteristics in the case where no pressure pad was used. Although the results clearly elucidated the effects of 
the U-geometry parameters on the spring-back/spring-go characteristics, the degree of importance of the U-geometry parameters, in relation to the spring-back/spring-go characteristics, could not be determined. The degree of importance of the U-geometry parameters is very important for die and process designs. Therefore, the statistical technique was needed to examine the degree of importance of the U-geometry parameters, in relation to the spring-back/spring-go characteristics.

\begin{tabular}{|c|c|c|c|}
\hline \multicolumn{4}{|c|}{ Workpiece length (mm) } \\
\hline \multirow{4}{*}{ 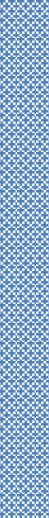 } & (1) 120 & (2) 125 & 130 \\
\hline & 'Reversed & Bending stress & Reversed \\
\hline & \multicolumn{3}{|c|}{ Length of generated stress distribution $(\mathrm{mm})$} \\
\hline & A: $2.63, B: 16.05$ & A: $2.60, B: 16.12$ & A: $2.63, B: 16.03$ \\
\hline \multirow[t]{3}{*}{ 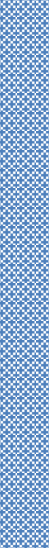 } & Beversed & 'Reversed & 'Reversed \\
\hline & \multicolumn{3}{|c|}{ Length of generated stress distribution $(\mathrm{mm})$} \\
\hline & $\begin{array}{l}\text { A: } 11.14, \text { B: } 11.16, \\
\text { C: } 4.21\end{array}$ & $\begin{array}{l}\text { A: } 11.09, B: 11.21, \\
\text { C: } 4.19\end{array}$ & $\begin{array}{l}\text { A: } 11.20, \text { B: } 11.15 \text {, } \\
\text { C: } 4.23\end{array}$ \\
\hline \multicolumn{4}{|c|}{ Mean stress (MPa) } \\
\hline & & -50 & 100 \\
\hline
\end{tabular}

Figure 12. Comparison of the stress distribution analyzed in the workpiece, before unloading, with respect to various workpiece lengths $\left(\theta: 90^{\circ}, R_{\mathrm{p}}: 7 \mathrm{~mm}, W: 30 \mathrm{~mm}, t: 3 \mathrm{~mm}, R_{\mathrm{ud}}: 5 \mathrm{~mm}\right)$.

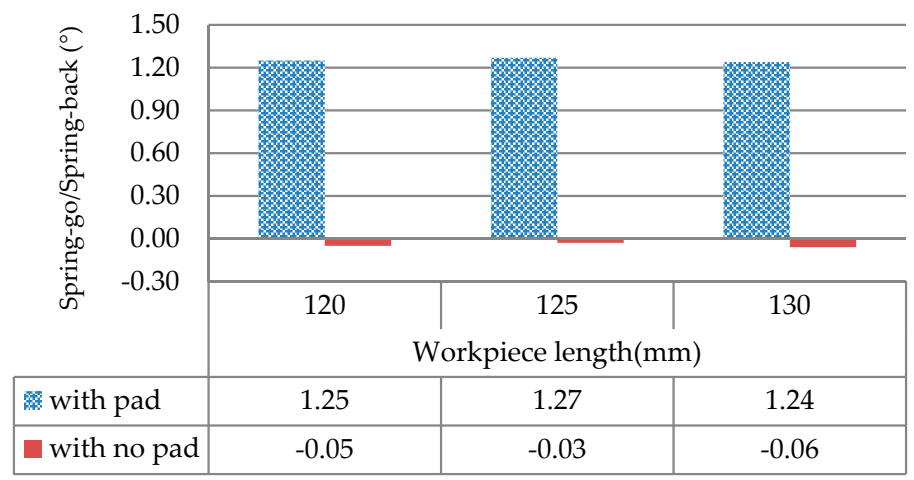

Figure 13. Comparison of the predicted spring-back/spring-go characteristics between the cases of U-bending with and without pressure pads, with respect to workpiece lengths $\left(\theta: 90^{\circ}, R_{\mathrm{p}}: 7 \mathrm{~mm}\right.$, $\left.W: 30 \mathrm{~mm}, t: 3 \mathrm{~mm}, R_{\mathrm{ud}}: 5 \mathrm{~mm}\right)$. 


\subsection{The Use of FEM Simulation and Its Validation}

To reduce the number of experiments for the examination of the degree of importance of the U-geometry parameters, FEM simulations were used. Therefore, validation of the accuracy of the FEM simulation results was necessary. Figure 14 shows examples of the comparison between bent parts, with and without pressure pads, obtained by FEM and experiments. The results showed the spring-back and spring-go characteristics formed where pressure pads and no pressure pads were used, respectively. In addition, as shown in Figure 15, additional bending conditions were also investigated. The analyzed bending angle was also compared with those obtained by the experiments. FEM simulation results showed the formation of the spring-back and spring-go characteristics, which corresponded well with the experiments, and the error, compared with that of the experimental results, was approximately $1 \%$. Next, workpiece thickness of the bent parts was also examined and compared with that which was obtained from the FEM simulation results. As the results in Figure 14 show, the FEM simulation results showed that the workpiece thickness, which corresponded well with the experiments and the error, compared with that from the experimental results, was approximately $1 \%$. The bending force was also compared with that obtained by the experiments, as shown in Figure 16. The bending force increased as the bending stroke increased due to the workpiece being largely bent. Next, after a bending stroke of approximately $12 \mathrm{~mm}$, the legs of the workpiece were pushed into the die using a punch and causing a small bending characteristic; this resulted in the decreases in the bending force. After the entire workpiece was moved to the die, the bending force was decreased to nearly zero, and it, again, increased when the bottom surface made contact with the die, and increased sharply when it was completely compressed. The FEM simulations were in good agreement with the experimental results, wherein the error was approximately $1 \%$.

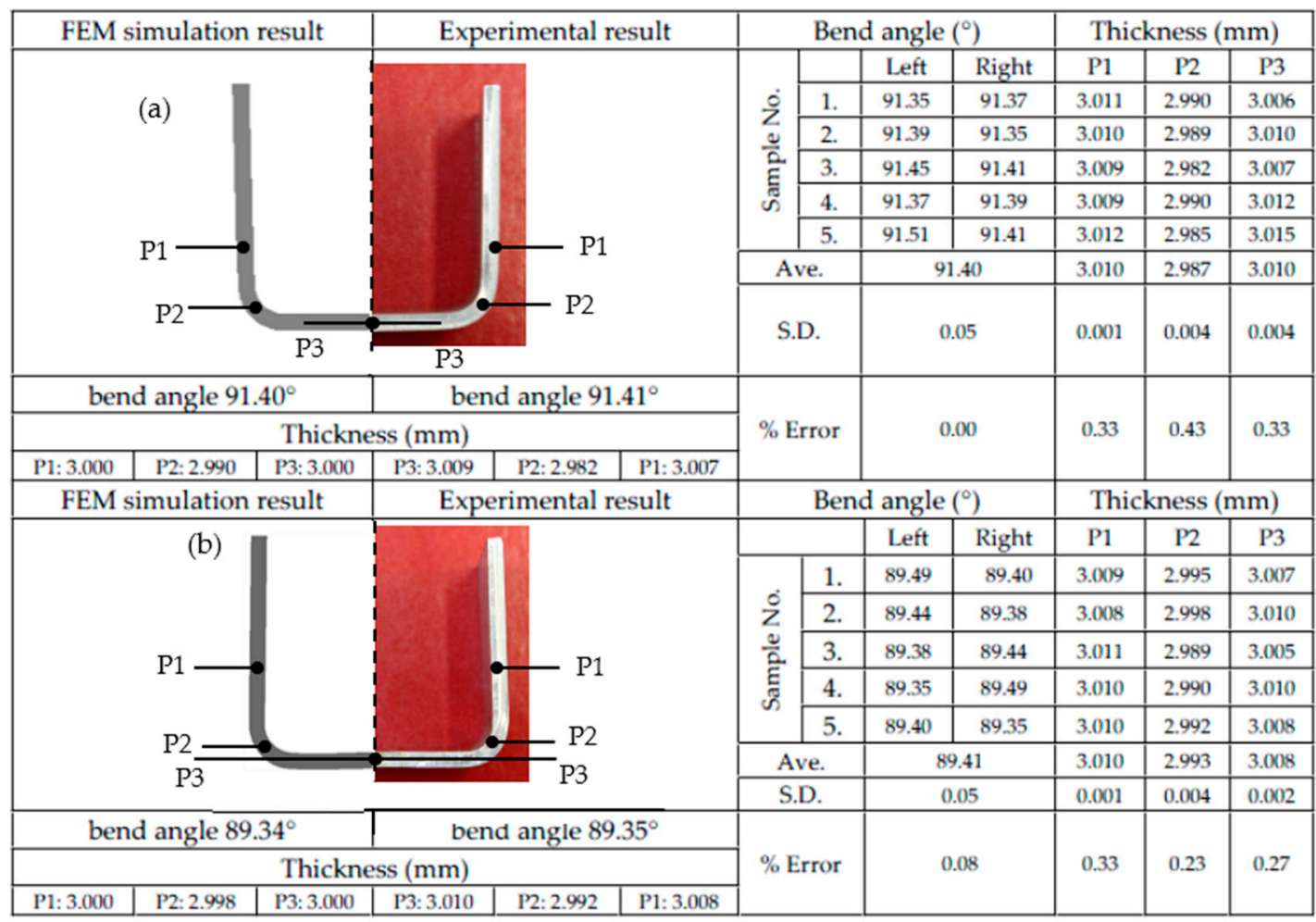

Figure 14. Comparison of the bent parts, obtained using FEM simulations and experiments: (a) with pressure pads; (b) without pressure pads $\left(\theta: 90^{\circ}, t: 3 \mathrm{~mm}, W P_{\mathrm{L}}: 120 \mathrm{~mm}, W: 40 \mathrm{~mm}, R_{\mathrm{p}}: 5 \mathrm{~mm}\right.$, $\left.R_{\mathrm{ud}}: 5 \mathrm{~mm}\right)$. SD: Standard deviation. 


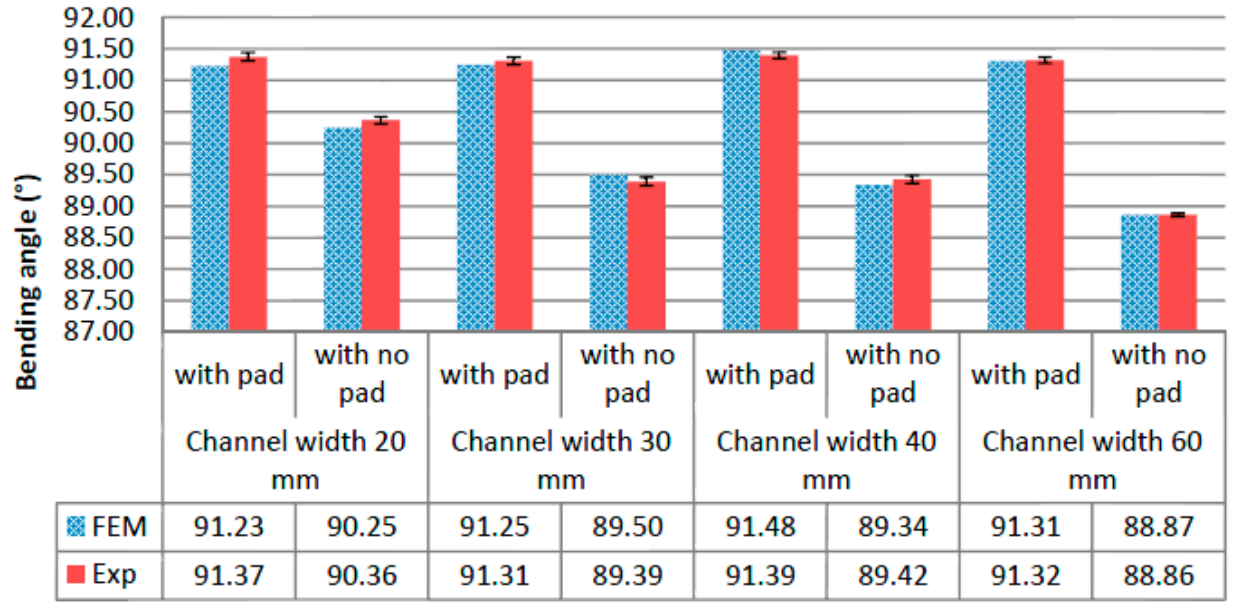

\footnotetext{
Remark:

Channel width $20 \mathrm{~mm}: W P_{L}=100 \mathrm{~mm}, R_{p}=7 \mathrm{~mm}$

Channel width $30 \mathrm{~mm}: W P_{L}=120 \mathrm{~mm}, R_{p}=7 \mathrm{~mm}$

Channel width $40 \mathrm{~mm}: W P_{L}=100 \mathrm{~mm}, R_{p}=5 \mathrm{~mm}$

Channel width $60 \mathrm{~mm}: W P_{L}=100 \mathrm{~mm}, R_{p}=7 \mathrm{~mm}$
}

Figure 15. Comparison of the bending angle between the FEM simulations and the experimental results $\left(\theta: 90^{\circ}, t: 3 \mathrm{~mm}, R_{\mathrm{ud}}: 5 \mathrm{~mm}\right)$.

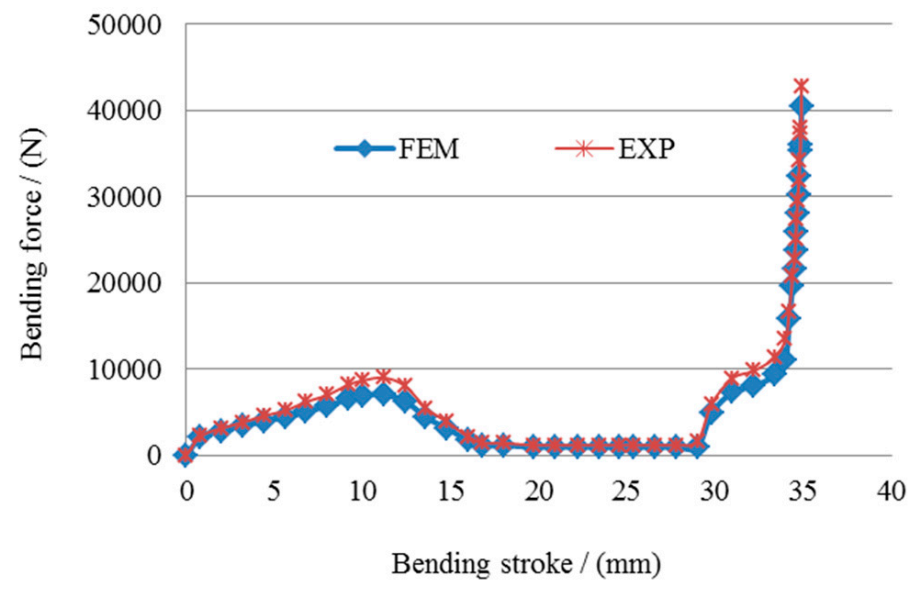

Figure 16. Comparison of bending forces between FEM simulations and experimental results $\left(\theta: 90^{\circ}\right.$, t: $3 \mathrm{~mm}, W P_{\mathrm{L}}: 130 \mathrm{~mm}, W: 60 \mathrm{~mm}, R_{\mathrm{p}}: 5 \mathrm{~mm}, R_{\mathrm{ud}}: 5 \mathrm{~mm}$, without pad). EXP: Experiment.

\subsection{Statistical Analysis}

On the basis of the central composite design technique, Table 3 shows the amounts of spring-back, analyzed using FEM simulations for both pressure pads and no pressure pads. Based on these bending conditions, to confirm the accuracy of the FEM simulation results, some bending conditions were chosen for experimentation. As shown in Figure 17, the FEM simulation results, again, showed the formation of the spring-back characteristics, which corresponded well with the experiments; the error compared with that from the experimental results was approximately $1 \%$. 
Table 3. The amounts of spring-back in cases where pressure pads and no pressure pads were used, analyzed using FEM simulations.

\begin{tabular}{|c|c|c|c|c|c|c|c|c|c|c|c|c|}
\hline \multirow{3}{*}{$\begin{array}{c}\text { FEM } \\
\text { No. }\end{array}$} & \multicolumn{10}{|c|}{ U-Geometry Parameters } & \multirow{2}{*}{\multicolumn{2}{|c|}{ Spring-Back $\left({ }^{\circ}\right)$}} \\
\hline & \multicolumn{2}{|r|}{$\theta$} & \multicolumn{2}{|c|}{$W_{\mathrm{p}}$} & \multicolumn{2}{|c|}{$R_{\mathrm{p}}$} & \multicolumn{2}{|r|}{$t$} & \multicolumn{2}{|c|}{$W P_{\mathrm{L}}$} & & \\
\hline & $\begin{array}{l}\text { with } \\
\text { Pad }\end{array}$ & $\begin{array}{c}\text { with } \\
\text { no Pad }\end{array}$ & $\begin{array}{l}\text { with } \\
\text { Pad }\end{array}$ & $\begin{array}{c}\text { with } \\
\text { no Pad }\end{array}$ & $\begin{array}{l}\text { with } \\
\text { Pad }\end{array}$ & $\begin{array}{c}\text { with } \\
\text { no Pad }\end{array}$ & $\begin{array}{l}\text { with } \\
\text { Pad }\end{array}$ & $\begin{array}{c}\text { with } \\
\text { no Pad }\end{array}$ & $\begin{array}{l}\text { with } \\
\text { Pad }\end{array}$ & $\begin{array}{c}\text { with } \\
\text { no Pad }\end{array}$ & $\begin{array}{l}\text { with } \\
\text { Pad }\end{array}$ & $\begin{array}{c}\text { with } \\
\text { no Pad }\end{array}$ \\
\hline 1 & 90 & 90 & 30 & 30 & 5 & 3 & 3 & 1 & 120 & 120 & 1.11 & 0.33 \\
\hline 2 & 120 & 90 & 30 & 30 & 5 & 3 & 3 & 1 & 120 & 130 & 0.29 & 0.80 \\
\hline 3 & 90 & 90 & 60 & 30 & 5 & 3 & 3 & 3 & 120 & 120 & 1.56 & 0.67 \\
\hline 4 & 120 & 90 & 60 & 30 & 5 & 3 & 3 & 3 & 120 & 130 & 0.34 & 0.93 \\
\hline 5 & 90 & 90 & 30 & 30 & 7 & 5 & 3 & 1 & 120 & 120 & 1.25 & 0.69 \\
\hline 6 & 120 & 90 & 30 & 30 & 7 & 5 & 3 & 1 & 120 & 130 & 0.32 & 0.93 \\
\hline 7 & 90 & 90 & 60 & 30 & 7 & 5 & 3 & 3 & 120 & 120 & 1.62 & 0.50 \\
\hline 8 & 120 & 90 & 60 & 30 & 7 & 5 & 3 & 3 & 120 & 130 & 0.49 & 0.78 \\
\hline 9 & 90 & 90 & 30 & 60 & 5 & 3 & 5 & 1 & 120 & 120 & 0.95 & 0.57 \\
\hline 10 & 120 & 90 & 30 & 60 & 5 & 3 & 5 & 1 & 120 & 130 & 0.06 & 0.52 \\
\hline 11 & 90 & 90 & 60 & 60 & 5 & 3 & 5 & 3 & 120 & 120 & 1.31 & 0.95 \\
\hline 12 & 120 & 90 & 60 & 60 & 5 & 3 & 5 & 3 & 120 & 130 & 0.04 & 0.96 \\
\hline 13 & 90 & 90 & 30 & 60 & 7 & 5 & 5 & 1 & 120 & 120 & 1.45 & 0.36 \\
\hline 14 & 120 & 90 & 30 & 60 & 7 & 5 & 5 & 1 & 120 & 130 & 0.33 & 0.42 \\
\hline 15 & 90 & 90 & 60 & 60 & 7 & 5 & 5 & 3 & 120 & 120 & 1.39 & 0.69 \\
\hline 16 & 120 & 90 & 60 & 60 & 7 & 5 & 5 & 3 & 120 & 130 & 0.37 & 0.55 \\
\hline 17 & 90 & 120 & 30 & 30 & 5 & 3 & 3 & 1 & 130 & 120 & 1.52 & 1.07 \\
\hline 18 & 120 & 120 & 30 & 30 & 5 & 3 & 3 & 1 & 130 & 130 & 0.24 & 1.74 \\
\hline 19 & 90 & 120 & 60 & 30 & 5 & 3 & 3 & 3 & 130 & 120 & 1.54 & 0.25 \\
\hline 20 & 120 & 120 & 60 & 30 & 5 & 3 & 3 & 3 & 130 & 130 & 0.36 & 0.16 \\
\hline 21 & 90 & 120 & 30 & 30 & 7 & 5 & 3 & 1 & 130 & 120 & 1.93 & 0.87 \\
\hline 22 & 120 & 120 & 30 & 30 & 7 & 5 & 3 & 1 & 130 & 130 & 0.27 & 1.56 \\
\hline 23 & 90 & 120 & 60 & 30 & 7 & 5 & 3 & 3 & 130 & 120 & 1.65 & 0.63 \\
\hline 24 & 120 & 120 & 60 & 30 & 7 & 5 & 3 & 3 & 130 & 130 & 0.47 & 0.53 \\
\hline 25 & 90 & 120 & 30 & 60 & 5 & 3 & 5 & 1 & 130 & 120 & 1.30 & 1.00 \\
\hline 26 & 120 & 120 & 30 & 60 & 5 & 3 & 5 & 1 & 130 & 130 & 0.08 & 1.87 \\
\hline 27 & 90 & 120 & 60 & 60 & 5 & 3 & 5 & 3 & 130 & 120 & 1.33 & 0.42 \\
\hline 28 & 120 & 120 & 60 & 60 & 5 & 3 & 5 & 3 & 130 & 130 & 0.05 & 0.38 \\
\hline 29 & 90 & 120 & 30 & 60 & 7 & 5 & 5 & 1 & 130 & 120 & 1.45 & 1.71 \\
\hline 30 & 120 & 120 & 30 & 60 & 7 & 5 & 5 & 1 & 130 & 130 & 0.33 & 1.31 \\
\hline 31 & 90 & 120 & 60 & 60 & 7 & 5 & 5 & 3 & 130 & 120 & 1.39 & 0.73 \\
\hline 32 & 120 & 120 & 60 & 60 & 7 & 5 & 5 & 3 & 130 & 130 & 0.34 & 0.45 \\
\hline 33 & 105 & 105 & 45 & 45 & 6 & 4 & 4 & 2 & 125 & 125 & 0.30 & 2.71 \\
\hline 34 & 90 & 90 & 45 & 45 & 6 & 4 & 4 & 2 & 125 & 125 & 1.52 & 2.53 \\
\hline 35 & 120 & 120 & 45 & 45 & 6 & 4 & 4 & 2 & 125 & 125 & 0.38 & 2.62 \\
\hline 36 & 105 & 105 & 30 & 30 & 6 & 4 & 4 & 2 & 125 & 125 & 0.41 & 1.50 \\
\hline 37 & 105 & 105 & 60 & 60 & 6 & 4 & 4 & 2 & 125 & 125 & 0.47 & 2.16 \\
\hline 38 & 105 & 105 & 45 & 45 & 5 & 3 & 4 & 2 & 125 & 125 & 0.42 & 2.15 \\
\hline 39 & 105 & 105 & 45 & 45 & 7 & 5 & 4 & 2 & 125 & 125 & 0.41 & 2.68 \\
\hline 40 & 105 & 105 & 45 & 45 & 6 & 4 & 3 & 1 & 125 & 125 & 0.33 & 1.65 \\
\hline 41 & 105 & 105 & 45 & 45 & 6 & 4 & 5 & 3 & 125 & 125 & 0.47 & 1.18 \\
\hline 42 & 105 & 105 & 45 & 45 & 6 & 4 & 4 & 2 & 120 & 120 & 0.46 & 2.16 \\
\hline 43 & 105 & 105 & 45 & 45 & 6 & 4 & 4 & 2 & 130 & 130 & 0.45 & 2.37 \\
\hline
\end{tabular}




\begin{tabular}{|c|c|c|c|c|c|}
\hline FEM simulation result & Experimental result & \multicolumn{4}{|c|}{ Bend angle $\left({ }^{\circ}\right)$} \\
\hline \multirow{8}{*}{ (a) } & & \multirow{6}{*}{ 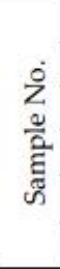 } & & Left & Right \\
\hline & & & 1. & 90.99 & 91.07 \\
\hline & & & 2. & 90.86 & 90.85 \\
\hline & & & 3. & 90.79 & 90.75 \\
\hline & & & 4. & 90.99 & 90.89 \\
\hline & & & 5. & 91.03 & 91.09 \\
\hline & & \multicolumn{2}{|c|}{ Ave. } & \multicolumn{2}{|c|}{90.93} \\
\hline & & \multicolumn{2}{|c|}{ S.D. } & \multicolumn{2}{|c|}{0.12} \\
\hline bend angle $90.96^{\circ}$ & bend angle $90.89^{\circ}$ & \multicolumn{2}{|c|}{$\%$ Error } & \multicolumn{2}{|c|}{0.03} \\
\hline FEM simulation result & Experimental result & \multicolumn{4}{|c|}{ Bend angle $\left({ }^{\circ}\right)$} \\
\hline \multirow{8}{*}{ (b) } & & & & Left & Right \\
\hline & & \multirow{5}{*}{$\begin{array}{l}\text { ż } \\
\text { है } \\
\text { हैँ } \\
\text { कू }\end{array}$} & 1. & 91.48 & 91.30 \\
\hline & & & 2. & 91.69 & 91.70 \\
\hline & & & 3. & 91.45 & 91.35 \\
\hline & & & 4. & 91.87 & 91.76 \\
\hline & & & 5. & 91.77 & 91.86 \\
\hline & & \multicolumn{2}{|c|}{ Ave. } & \multicolumn{2}{|c|}{91.62} \\
\hline & & \multicolumn{2}{|c|}{ S.D. } & \multicolumn{2}{|c|}{0.21} \\
\hline bend angle $91.54^{\circ}$ & bend angle $91.35^{\circ}$ & \multicolumn{2}{|c|}{$\%$ Error } & \multicolumn{2}{|c|}{0.09} \\
\hline FEM simulation result & Experimental result & \multicolumn{4}{|c|}{ Bend angle $\left({ }^{\circ}\right)$} \\
\hline \multirow{8}{*}{ (c) } & & & & Left & Right \\
\hline & & \multirow{5}{*}{ 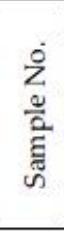 } & 1. & 120.43 & 120.28 \\
\hline & & & 2. & 120.93 & 121.10 \\
\hline & & & 3. & 120.92 & 120.85 \\
\hline & & & 4. & 120.87 & 121.00 \\
\hline & & & 5. & 120.95 & 120.79 \\
\hline & & \multicolumn{2}{|c|}{ Ave. } & \multicolumn{2}{|c|}{120.81} \\
\hline & & \multicolumn{2}{|c|}{ S.D. } & \multicolumn{2}{|c|}{0.26} \\
\hline bend angle $120.63^{\circ}$ & bend angle $120.85^{\circ}$ & \multicolumn{2}{|c|}{$\%$ Error } & \multicolumn{2}{|c|}{0.15} \\
\hline
\end{tabular}

Figure 17. Comparison of the bent parts, obtained using FEM simulations and experiments: (a) without pressure pads $\left(\theta: 90^{\circ}, t: 3 \mathrm{~mm}, W P_{\mathrm{L}}: 130 \mathrm{~mm}, W: 60 \mathrm{~mm}, R_{\mathrm{p}}: 3 \mathrm{~mm}, R_{\mathrm{ud}}: 5 \mathrm{~mm}\right)$; (b) with pressure pads $\left(\theta: 90^{\circ}, t: 3 \mathrm{~mm}, W P_{\mathrm{L}}: 120 \mathrm{~mm}, W: 60 \mathrm{~mm}, R_{\mathrm{p}}: 5 \mathrm{~mm}, R_{\mathrm{ud}}: 5 \mathrm{~mm}\right)$; (c) with no pressure pads $\left(\theta: 120^{\circ}, t: 3 \mathrm{~mm}, W P_{\mathrm{L}}: 120 \mathrm{~mm}, W: 30 \mathrm{~mm}, R_{\mathrm{p}}: 5 \mathrm{~mm}, R_{\mathrm{ud}}: 5 \mathrm{~mm}\right) . \mathrm{SD}$ : Standard deviation.

To investigate the degree of importance of the U-geometry parameters on the spring-back characteristics, based on the spring-back prediction amounts, ANOVA was carried out. The sums of squares due to the variations of the overall mean $\left(S S_{\text {total }}\right)$ and regarding the mean of the U-geometry parameters $\left(S S_{\text {treatment }}\right)$ in the cases where pressure pads and no pressure pads were used, were calculated and are listed in Table 4 . The percentage contributions were calculated, according to Equation (1), and are listed in Table 4; these values were generally applied for considering the degree of importance of each parameter. The results showed that, in the case of using pressure pads, the percentage contribution to the bend angle was the largest, followed by workpiece thickness and tool radius, with their percentage contributions being $91.07 \%, 2.01 \%$ and $1.37 \%$, respectively. These results indicated that the U-geometry parameters of the bend angle had the most influence on the spring-back characteristic, followed by workpiece thickness and tool radius, respectively. These results corresponded well with the stress distribution analyses, as previously mentioned; additionally they confirmed that channel width and workpiece length rarely had any effects on 
spring-back characteristics in the case where pressure pads were used. On the other hand, in the case where no pressure pads were used, the percentage contributions of channel width, workpiece thickness, and bend angle were $60.93 \%, 16.96 \%$ and $1.81 \%$, respectively. These results showed that the U-geometry parameters of the channel width had the most influence on the spring-back characteristics, followed by workpiece thickness and bend angle, respectively. In the case of where no pressure pads were used, this result corresponded well with the stress distribution analyses, as previously mentioned; they again confirmed that tool radius and workpiece length rarely had any effects on spring-back characteristics in the case where no pressure pad was used. As these results indicated, the bend angle and channel width have a major influence in the cases where pressure pads and no pressure pads are used, respectively. These statistical results indicate that the U-geometry parameters affected spring-back characteristics differently in the case where pressure pads and no pressure pads were used. It could be explained that, owing to the different bending mechanisms between bending with pads and without pads, there were no bending characteristics formed across the punch radius during the bending phase in the case where pressure pads were used, but it was formed in the case where no pressure pads were used. Therefore, the U-geometry parameters, which directly affected these bending mechanisms, were different. Specifically, there were no stresses generated on the bottom surface in the case of pressure pads being used, resulting in the spring-back characteristics, though they only depended on the stress generated on the bending allowance and leg zones. Therefore, as mentioned previously, the U-geometry parameters of the bend angle, workpiece thickness, and tool radius, which greatly affected these zones, had a great influence on the spring-back characteristics. On the other hand, excluding the generated stress on the bending allowance and leg zones, the bending and reversed bending stresses commonly generated on the bottom surface, in the case of pressure pads being used, resulted in the spring-back characteristics not being dependent only on the stresses generated on the bending allowance and leg zones, but also dependent on the stresses generated on the bottom surface. These generated stresses on the bottom surface zone were based on the bending characteristics formed across the punch radius during the bending phase. Therefore, as mentioned previously, the U-geometry parameters of channel width, workpiece thickness, and bend angle, which greatly affected these zones, had a great deal of influence on the spring-back characteristics.

Table 4. Percentage contributions.

\begin{tabular}{ccccc}
\hline Parameters & \multicolumn{2}{c}{$S S_{\text {treatment }}$} & \multicolumn{2}{c}{ \% Contributions } \\
\cline { 2 - 5 } & with Pad & with no Pad & with Pad & with no Pad \\
\hline Bend angle $(\theta)$ & 12.52 & 0.39 & 91.07 & 1.81 \\
Workpiece thickness $(t)$ & 0.28 & 1.10 & 2.01 & 5.11 \\
Tool radius $\left(R_{\mathrm{p}}\right)$ & 0.19 & - & 1.37 & - \\
Channel width $(W)$ & - & 0.01 & - & 0.05 \\
Workpiece length $\left(W P_{\mathrm{L}}\right)$ & - & 0.14 & - & 0.66 \\
Bend angle $(\theta) \times$ Bend angle $(\theta)$ & 0.76 & - & 5.55 & - \\
Channel width $(W) \times$ Channel width $(W)$ & - & 13.17 & - & 60.93 \\
Workpiece thickness $(t) \times$ Workpiece thickness $(t)$ & - & 3.67 & - & 16.96 \\
Bend angle $(\theta) \times$ Workpiece thickness $(t)$ & - & 2.82 & - & 13.05 \\
Workpiece thickness $(t) \times$ Workpiece length $\left(W P_{\mathrm{L}}\right)$ & - & 0.31 & - & 1.43 \\
\hline Total & 13.75 & 21.61 & 100.00 & 100.00 \\
\hline
\end{tabular}

\section{Conclusions}

In the present study, in order to examine the degree of importance of U-geometry parameters, including channel width, workpiece thickness, bend angle, tool radius, and workpiece length, in relation to the spring-back characteristics, FEM simulations, in association with statistical analyses of a central composite design, and ANOVA, were applied. The effects of the U-geometry parameters in the U-bending process, with and without pressure pads, were investigated using FEM simulations. First, on the basis of stress distribution analyses, the FEM simulation results clearly identified the 
difference of the bending mechanism and the effects of the U-geometry parameters on the spring-back characteristics of the U-bending process, with and without pressure pads. Specifically, the FEM simulation results clearly revealed that channel width and workpiece length rarely had any effects on the change in bending and reversed bending stresses in the case where pressure pads were used. Again, in the case where no pressure pads were used, the workpiece length rarely had any effects on the change in the bending and reversed bending stresses. However, the FEM simulation results could only elucidate the tendency of effects for each U-geometry parameter on the spring-back characteristics. Next, by using the central composite design and ANOVA, the degree of importance of the U-geometry parameters, in relation to the spring-back characteristics, could be obtained. The ANOVA results illustrated the influence of each U-geometry parameter on the spring-back characteristics, together with their calculated percentage contributions. The bend angle had the most influence in the case of pressure pads being used, followed by workpiece thickness and tool radius, respectively. On the other hand, the ANOVA results illustrated the influence of each U-geometry parameter on the spring-back characteristics, together with their calculated percentage contributions; channel width had the most influence in the case of no pressure pads being used, followed by workpiece thickness and bend angle, respectively. Laboratory experiments were carried out and FEM simulation results, as validated by laboratory experiments, showing a good agreement with the experimental results. The error in the bend angle, compared with the laboratory experimental results, was approximately $1 \%$. The analyzed bending forces were also compared with that obtained by experiments, and showed a good agreement with the experimental results, in which the error was approximately $1 \%$. Therefore, this technique could be applied as a tool for quality control of U-bent parts, based on spring-back characteristics, by optimizing the U-geometry parameter design.

Acknowledgments: This research was partially supported by a Grant from the Higher Education Research Promotion and National Research University Project of Thailand, Office of the Higher Education Commission, under Grant No. 56000519 and Grant No. 57000618. The authors thank Nopnarong Sirisatien for his advice in this study. The authors also thank graduate students, Pakkawat Komolruji, and Arkarapon Sontamino, for their help in this study.

Author Contributions: Wiriyakorn Phanitwong and Sutasn Thipprakmas conceived and designed the experiments; Wiriyakorn Phanitwong and Untika Boochakul performed the experiments; Wiriyakorn Phanitwong, Untika Boochakul and Sutasn Thipprakmas analyzed the data; Wiriyakorn Phanitwong and Sutasn Thipprakmas wrote the paper.

Conflicts of Interest: The authors declare no conflict of interest.

\section{References}

1. Zong, Y.Y.; Liu, P.; Guo, B.; Shan, D. Springback evaluation in hot V-bending of Ti-6Al-4V alloy sheets. Int. J. Adv. Manuf. Technol. 2015, 76, 577-585. [CrossRef]

2. Leu, D.K. Position deviation and springback in V-die bending process with asymmetric dies. Int. J. Adv. Manuf. Technol. 2015, 79, 1095-1108. [CrossRef]

3. Dilip Kumar, K.; Appukuttan, K.K.; Neelakantha, V.L.; Naik, P.S. Experimental determination of spring back and thinning effect of aluminum sheet metal during L-bending operation. J. Mater. Des. 2014, 56, 613-619. [CrossRef]

4. Lim, H.; Lee, M.G.; Sung, J.H.; Kim, J.H.; Wagoner, R.H. Time dependent springback of advanced high strength steels. Int. J. Plast. 2012, 29, 42-59. [CrossRef]

5. Thipprakmas, S. Finite element analysis on the coined-bead mechanism during the V-bending process. Mater. Des. 2011, 32, 4909-4917. [CrossRef]

6. Thipprakmas, S. Finite element analysis of punch height effect on V-bending angle. Mater. Des. 2010, 32, 4430-4436. [CrossRef]

7. Thipprakmas, S. Finite element analysis of sided coined-bead technique in precision V-bending process. Int. J. Adv. Manuf. Technol. 2013, 65, 679-688. [CrossRef]

8. Jiang, H.J.; Dai, H.L. A novel model to predict U-bending spring-back and time-dependent spring-back for a HSLA steel plate. Int. J. Adv. Manuf. Technol. 2015, 81, 1055-1066. [CrossRef] 
9. Thipprakmas, S.; Boochakul, U. Comparison of spring-back characteristics in symmetrical and asymmetrical U-bending processes. Int. J. Precis. Eng. Manuf. 2015, 16, 1441-1446. [CrossRef]

10. Phanitwong, W.; Thipprakmas, S. Centered coined-bead technique for precise U-bent part fabrication. Int. J. Adv. Manuf. Technol. 2015, 84, 2139-2150. [CrossRef]

11. Li, H.; Chen, J.; Yang, J. Experiment and numerical simulation on delamination during the laminated steel sheet forming processes. Int. J. Adv. Manuf. Technol. 2013, 68, 641-649. [CrossRef]

12. Nanu, N.; Brabie, G. Analytical model for prediction of springback parameters in the case of $U$ stretch-bending process as a function of stresses distribution in the sheet thickness. Int. J. Mech. Sci. 2012, 64, 11-21. [CrossRef]

13. Lee, J.Y.; Lee, J.W.; Lee, M.G.; Barlat, F. An application of homogeneous anisotropic hardening to springback prediction in pre-strained U-draw/bending. Int. J. Solids Struct. 2012, 49, 3562-3572. [CrossRef]

14. Thipprakmas, S.; Phanitwong, W. Finite element analysis of bending mechanism and spring-back/spring-go feature in various U-bending processes. Steel Res. Int. 2012, 351-354.

15. Seong, D.Y.; Jung, C.G.; Yang, D.Y.; Ahn, J.; Na, S.J.; Chung, W.J.; Kim, J.H. Analysis of core shear stress in welded deformable sandwich plates to prevent de-bonding failure during U-bending. J. Mater. Process. Technol. 2010, 210, 1171-1179. [CrossRef]

16. Marretta, L.; Lorenzo, R.D. Influence of material properties variability on spring-back and thinning in sheet stamping processes: A stochastic analysis. Int. J. Adv. Manuf. Technol. 2010, 51, 117-134. [CrossRef]

17. Tang, B.; Zhao, G.; Wang, Z. A mixed hardening rule coupled with Hill48' yielding function to predict the spring-back of sheet U-bending. Int. J. Mater. Form. 2008, 1, 169-175. [CrossRef]

18. Zhang, D.; Cui, Z.; Ruan, X.; Li, Y. An analytical model for predicting spring back and side wall curl of sheet after U-bending. Comput. Mater. Sci. 2007, 38, 707-715. [CrossRef]

19. Phanitwong, W.; Thipprakmas, S. Development of anew spring-back factor for a wiping die bending process. Mater. Des. 2016, 89, 749-758. [CrossRef]

20. Lange, K. Handbook of Metal Forming; McGraw-Hill: New York, NY, USA, 1985; pp. 1-35.

(C) 2017 by the authors. Licensee MDPI, Basel, Switzerland. This article is an open access article distributed under the terms and conditions of the Creative Commons Attribution (CC BY) license (http:/ / creativecommons.org/licenses/by/4.0/). 